Revue de l'Institut des langues et cultures

d'Europe, Amérique, Afrique, Asie et Australie

26 | 2016

Mémoire, vérité et justice en Uruguay

\title{
Efectos tardíos de la tortura. Reparación y aportes desde la psicología
}

After Effects of Torture. Reparation and Contribution from Psychology

Effets à long terme de la torture. Réparation et apports de la psychologie

\section{María Celia Robaina}

\section{CpenEdition}

\section{Journals}

Edición electrónica

URL: http://journals.openedition.org/ilcea/3927

DOI: 10.4000/ilcea.3927

ISSN: 2101-0609

Editor

UGA Éditions/Université Grenoble Alpes

Edición impresa

ISBN: 978-2-84310-334-6

ISSN: $1639-6073$

Referencia electrónica

María Celia Robaina, «Efectos tardíos de la tortura. Reparación y aportes desde la psicología », ILCEA [En línea], 26 | 2016, Publicado el 07 julio 2016, consultado el 19 abril 2019. URL : http:// journals.openedition.org/ilcea/3927 ; DOI : 10.4000/ilcea.3927

Este documento fue generado automáticamente el 19 abril 2019.

(c) ILCEA 


\title{
Efectos tardíos de la tortura. Reparación y aportes desde la psicología
}

\author{
After Effects of Torture. Reparation and Contribution from Psychology \\ Effets à long terme de la torture. Réparation et apports de la psychologie
}

María Celia Robaina

\section{Acerca de la tortura}

1 En esta contribución se desarrollan algunos resultados de un estudio basado en entrevistas en profundidad realizadas a psicólogos y psiquiatras responsables de ofrecer atención en salud mental a ex prisioneras/os políticas/os. Se buscó conocer los efectos de la tortura y la prisión política que aún persisten. Por otra parte, se consultó a los entrevistados sobre sus percepciones respecto a ciertas políticas públicas de Reparación.

La dictadura se propuso construir un nuevo «proyecto de nación», al decir de Giorgi (1995), basado en el principio de autoridad, el ataque a las iniciativas colectivas y la redefinición de las Fuerzas Armadas como tutores y reservorio de la «moral nacional». Según SERPAJ (1989) la acción represiva se dirigió a un grupo heterogéneo y cada vez más vasto. La genérica categoría «subversivo» calificaba como tales, desde miembros de organizaciones armadas hasta personas de organizaciones con actividad pacífica e incluso ni siquiera política. Todos podían habitar las cárceles y ser objeto de torturas, so pretexto de haber sido declarados «enemigos de la patria».

Las principales técnicas que utilizaron quienes detentaban el poder, fueron la tortura sistemática y la prisión política prolongada. La prisión en sí misma se transformó en un sistema torturante, planificado y sistemático, en el que se aplicaron diversos dispositivos con el propósito de provocar dolor físico y/o psicológico y producir daños. Al hablar de tortura se tomará la definición que propone Naciones Unidas: 


\begin{abstract}
A los efectos de la presente Convención, se entenderá por el término «tortura» todo acto por el cual se inflija intencionadamente a una persona dolores o sufrimientos graves, ya sean físicos o mentales, con el fin de obtener de ella o de un tercero información o una confesión, de castigarla por un acto que haya cometido, o se sospeche que ha cometido, o de intimidar o coaccionar a esa persona o a otras, o por cualquier razón basada en cualquier tipo de discriminación, cuando dichos dolores o sufrimientos sean infligidos por un funcionario público u otra persona en el ejercicio de funciones públicas, a instigación suya, o con su consentimiento o aquiescencia. (1987, Parte I, artículo 1)
\end{abstract}

Quienes estuvieron recluidos por motivos políticos fueron objeto de destrato, humillación y martirios. La mayoría de los prisioneros diferencian un tiempo de torturas físicas y psicológicas de mayor envergadura ubicada en el primer periodo posterior a la detención, realizada generalmente en centros clandestinos. Pero la tortura no cesaba cuando eran procesados y trasladados a las diversas cárceles. Fueron sometidos a un sistema torturante, en forma continua hasta el momento de su liberación, la que se producía luego de varios años. Según SERPAJ (1989), el tiempo de reclusión promedio fue de 6,6 años para los hombres y de 5,7 años para las mujeres.

5 En términos psíquicos la tortura se puede entender como una práctica científicamente planificada para desmontar los mecanismos de la identificación primaria (Gil et al., 1990), que se propone llevar al torturado a la destrucción de su yo y de su mundo simbólico, de modo que esas singulares vivencias queden en un registro anterior al del lenguaje. Aunque la tortura se aplica sobre el cuerpo, persigue el objetivo de transformar a la persona en alguien sin ideales ni expectativas, sin voluntad y sin confianza, convertirlo en un ser sometido. A través de la aplicación del terror se busca fundar un sistema de control y destruir al «opositor». La vivencia de soledad extrema durante la tortura física, está dada porque afecta el núcleo más personal y básico de la identidad como lo es el cuerpo (Kordon et al., 2002).

[...] Pero las figuras del mal (la tortura, desaparición, guerra, genocidio) no generan experiencia ni enseñanza, sino vacío representacional. La experiencia catastrófica es un agujero en la continuidad representacional inherente a la vida psíquica. El horror y el dolor extremo no generan experiencia sino espanto, no genera representaciones y relato sino vacío representacional y por consiguiente lo ocurrido es difícilmente transmisible y compartible. (Viñar, 2011: 58)

El tiempo de la tortura es un tiempo no cronológico, caótico. Tiempo eterno en el que la persona se pregunta "cuánto más será capaz de resistir». Los individuos además de ser diferentes, llegan a esa experiencia extrema con un cúmulo de circunstancias de vida heterogéneas, por lo que disponen de recursos desparejos, tanto físicos como psíquicos. Nadie sabe a ciencia cierta hasta cuándo o cuánto podrá soportar, lo que se transforma en un pensamiento recurrente y desesperante. Algunos se defienden a través de reacciones físicas, otros escapan de la realidad por medio del delirio, los más se sostienen en sus afectos, en sus grupos de pertenencia o en sus convicciones. Todo se pone a prueba, la resistencia del cuerpo, la fortaleza psíquica, la autoestima, la coherencia consigo mismo, la lealtad al grupo, el afecto por los compañeros, la moral, los ideales. La tortura significa una macabra pulseada en la que el sujeto descubre sus recursos y se enfrenta a sus aspectos más frágiles.

7 El equipo de Salud Mental del Centro de Estudios Legales y Sociales (CELS, 1989), propone una explicación que permite comprender el porqué de lo inenarrable de estas experiencias. Establece un paralelismo entre las primeras etapas de indefensión humana en las que la vida depende de un Otro que al libidinizarlo posibilita la cohesión de su Yo, y 
la tortura, en la que el sujeto será llevado a una situación de máxima indefensión, en la que el torturador será el único Otro disponible al que el sujeto tendrá acceso. La humillación y la culpa por esa dependencia involuntaria con quien busca destruirlo, provocarían vivencias que entrarían en la categoría de lo inenarrable.

Los represores se proponen doblegar a sus víctimas para llevarlas a la delación y al arrepentimiento. Sin embargo ese objetivo, según los testimonios de los ex prisioneros, mayormente no fue alcanzado. Es frecuente que los ex detenidos reafirmen su convicción acerca de las razones que los llevó a la militancia política, así como también manifiesten satisfacción por haber podido resistir a las torturas. Quizá por ello, los perpetradores se propusieran la tarea de ocasionarles daño psíquico o «quebrarlos» durante el tiempo que estuvieron recluidos (Gil et al., 1990).

Los martirios fueron constantes, la arbitrariedad y la confusión buscaban que los presos no pudieran anticipar lo que vendría y por lo tanto prepararse para ello. Martín (2002) detalla una serie de medidas torturantes habituales en las cárceles políticas y las asemeja a las prácticas nazis en los campos de exterminio: rutinas de vida arbitrarias (alimentarias, higiene, sueño), dificultades para el contacto con el afuera (restricción de visitas, censuras, lecturas), criterios de selección psicopatológicos o por diferencias políticas para elegir quienes compartirían la misma celda, identificación con un número, uso del uniforme y corte de pelo.

Sin embargo, no debe perderse de vista que aunque la tortura fue aplicada en el cuerpo de algunos sujetos, ésta perseguía fines políticos. La tortura significó dentro del imaginario social una representación social potente que tuvo el fin de infundir miedo en toda la población. El régimen se propuso eliminar todo intento de rebeldía y oposición para facilitar el objetivo de domesticar a la sociedad. Desde este lugar se entiende que los efectos no se concentran solamente en quienes fueron sus víctimas directas. Por lo que se hace necesario un real procesamiento de lo traumático social que deje enseñanzas colectivas, proceso que permitirá aliviar a quienes fueron sus víctimas directas al tiempo que posibilitará construir una democracia más saludable.

\section{¿Qué efectos se observan en la actualidad?}

El horror, incluido en el psiquismo como cuerpo extraño, se expresa en el gesto, en la mirada, a veces en el síntoma, sobre todo físico, y en otros rasgos anclados en el carácter, como la aprensión, el temor ante un gesto, una mirada. El clima afectivo que se transmite es de desconfianza, incluso hacia sus propios hijos. Son aquellas marcas no significables que se transmitirán a los niños. (Ulriksen, 2006: 124, 125)

El 58,33\% de los entrevistados afirma que existen vinculaciones entre los motivos por los que consultan actualmente los ex prisioneros y aspectos referidos a las experiencias pasadas, o a las dificultades actuales para el procesamiento social de aquella catástrofe social. Sin embargo, entre ellos se observan variaciones respecto al énfasis que le otorgan a los mismos en el transcurso de las psicoterapias.

Los principales motivos de consulta observados por los entrevistados entre 2007 y 2012, son: a) conflictos en los vínculos significativos $58,33 \%$-se aclara que antes se observaban mayoritariamente en la pareja y hoy se refieren al vínculo con los hijos-; b) depresión $50 \%$-que aparece con mayor prevalencia en mujeres-; c) ansiedad 33,33 \%.

Del análisis de estos motivos se desprenden algunas conflictivas predominantes. 
14 a) El mayor daño se observa en los conflictos vinculares dentro de la familia, causados por la ruptura de la integración familiar y la transmisión transgeneracional de aspectos de lo traumático que podrían llegar hasta la tercera generación. Se resalta la necesidad de un mayor procesamiento en el ámbito familiar a fin de menguar la intensidad en la transmisión de lo traumático, en tanto lo que no se simboliza a través de la palabra, corre el riesgo de ser transmitido por medio de actos, gestos o imposturas.

La prisión prolongada, la persecución que llevó a muchos a vivir en clandestinidad o marchar al exilio, impuso un fuerte desarraigo entre las víctimas y sus respectivos núcleos familiares (primarios y/o secundarios). Las familias quedaron divididas, hasta la actualidad hay integrantes en diversos países. Hubo peleas, enojos y rencores, discrepancias políticas, mala resolución de conflictos, culpas y culpabilizaciones. Es posible inferir que algo de la violencia sufrida pudo haber quedado encorsetado entre los miembros del grupo familiar. La situación de encarcelamiento privó a algunos de ejercer roles parentales en las primeras etapas del desarrollo de sus hijos. Quizá hoy cuando los ex presos realizan balance de sus vidas, sopesan la distancia que se produjo en estos vínculos. Los hijos, por su parte, con frecuencia acusan a los padres de haberlos abandonado y los culpan por su elección militante. La prisión impuso una distancia profunda entre padres e hijos, muchos nunca pudieron recuperar el tiempo perdido. Como si hubiese quedado un «agujero» en la trama vincular que se resignifica cuando pasan los hijos por la experiencia de ser padres. Los terapeutas sostienen que a modo de acercar ambas visiones sobre lo acontecido, observan que mayoritariamente, no hubo en los padres deseo de abandonar a los hijos, que el quiebre fue impuesto por el terror. Asimismo, desde un análisis histórico cabe preguntarse por el margen de elección que tuvieron aquellos jóvenes militantes de las décadas de los 60 y 70, quienes se vieron envueltos por un contexto político mundial dicotómico, maniqueista y utópico.

Es posible que muchos padres o madres al ser liberados hayan tenido serias dificultades para cuidar y sostener material y afectivamente a sus hijos, tanto por los daños materiales y emocionales que dejó en ellos el encarcelamiento, como por la discriminación social de la que fueron objeto. En menor grado algunos observan el impacto de la violencia absorbida. Se plantea como hipótesis, que sería justamente en los vínculos más cercanos donde podrían emerger en bruto las marcas: desconfianza, temor a que el otro se acerque tanto que dañe, impulsividad, violencia introyectada. Se podría pensar que los ex prisioneros al ser depositarios de una violencia tan brutal, podrían transformarse en portadores o transmisores de la misma, y que sería en los vínculos más cercanos donde se podría vislumbrar aquello que no pudo ser simbolizado ni metabolizado psíquicamente.

b) El $50 \%$ de los entrevistados asocian la demanda de consulta psicológica con la crisis vital que surge en el entorno de los procesos jubilatorios; en su mayoría los ex prisioneros sobrepasan los 60 años de edad. Etapa de la vida caracterizada por promover balances, cierres, duelos, así como, por reformular proyectos de vida. La militancia otorgó sentido y continuidad a la vida; es en ese contexto que se entiende la prisión, como prueba de su compromiso militante. Quizá el encierro esté entre las experiencias más dolorosas que les tocó vivir, algunos se preguntarán si valió la pena tanto sufrimiento; otros, si se alcanzaron los cambios que se perseguían a nivel social -referidos a la construcción de un mundo más justo. Varios entrevistados observan sentimientos de desilusión; señalan que los pacientes emiten fuertes críticas al gobierno, debido en parte, a que esperaban que éste hicieran cambios más profundos en el seno de la sociedad y a que llevaran 
adelante una política de reparación de los daños que estuviese a la altura de los acuerdos alcanzados en los organismos internacionales de derechos humanos.

c) Entre las conflictivas psíquicas se observó lo que se nominará la emergencia de lo traumático. Es decir aquella angustia experimentada en los eventos traumáticos que no pudo ser ligada a palabras, que aflora en el presente. La vuelta al trauma se puede observar a través de: flashback de recuerdos terroríficos, acting out, desplazamientos de aspectos persecutorios en personas del presente, sintomatologías en el cuerpo -con alta frecuencia en enfermedades psicosomáticas, autoinmunes o vasculares. La elaboración del trauma se propondrá como un fin perseguido por el proceso terapéutico, recordar para no repetir. Se buscará resignificar, volver a sentir las emociones que giraron en torno al trauma, ligar los afectos a sus respectivas representaciones, poner palabras a las vivencias, simbolizar -aunque sea en parte-, lo que no pudo acceder a la palabra a fin de otorgarle nuevos significados.

d) Por otra parte se observó lo que se llamará conflictivas psicosociales que se suscitan ante al procesamiento sociopolítico de los traumatismos. Situaciones en las que la persona relaciona lo que ocurre en el espacio público y social con la movilización interna que esto le produce, o a la sintomatología física que le acarrea. Los profesionales observan a los pacientes más movilizados cuando ocurren sucesos políticos que dificultan el procesamiento de ese pasado, lo que confirma la idea de que los traumatismos psicosociales para que puedan ser procesados psíquicamente en los sujetos, necesitan ser abordados conjuntamente en forma social, porque se hallan interconectados. Es posible mostrar lo que fue silenciado cuando la sociedad lo reconoce y le otorga un lugar legitimado. Probablemente, las personas para continuar con sus proyectos de vida, debieran disociar o negar ciertos recuerdos $\mathrm{y}$, concomitantemente, controlar las emociones asociadas a ellos. Sin embargo, cuando el horror reaparece en forma intempestiva en el espacio público a través de los medios de comunicación, aquellos equilibrios alcanzados se tambalean y resurgen emociones que pueden desbordar.

Hay acuerdo en la idea de que la tortura física y/o psicológica, así como la prisión política, son experiencias límites que no dejan a nadie exento de efectos, lo que no siempre implicará daños patológicos. Los profesionales en su mayoría manifiestan rechazo por el uso de la terminología médica, como ser: secuela, síntoma o patología. Se considera que no se aplica a esta población, aplicarla significaría medicalizar eventos de índole sociopolíticos. Se entienden los efectos no como enfermedades sino como modos de respuesta frente a traumatismos psicosociales. Todos coinciden en que estas vivencias devastadoras podrían reactualizarse ante situaciones dolorosas del presente, tanto de índole personal como colectiva o social.

\section{Efectos tardíos de la tortura}

Se detallan los efectos observados por los clínicos en orden de prevalencia:

a) El $75 \%$ de los entrevistados sostiene que el principal impedimento observado es la desconfianza. La que surge de la experiencia límite de haber conocido la crueldad humana en su máxima expresión. La tortura lleva a desarrollar fuertes mecanismos de alerta, a sospechar del otro, aún de sí mismo. Conocer seres humanos capaces de dar rienda suelta a los impulsos más bajos y ruines, que ponen en acción aquello que es necesario reprimir para vivir en sociedad, es una experiencia que se halla en el punto culmine de la 
devastación (Mangado \& Robaina, 2012). Es haber sido ubicado por un tercero en la posición de total despojo y haber bordeado la orilla que separa la vida de la muerte. Se trata de experiencias catastróficas que afectan a la persona en todas sus dimensiones: afectivas, vinculares, intelectuales, sensoriales, corporales, sociales. La dificultad para construir lazos de confianza podrá afectar todo los vínculos del sujeto: en algunos podrá menguar su mundo de relaciones a niveles extremos, produciéndose un círculo que podría llevarlos a quedar aislados, repitiéndose así la experiencia de la vida en prisión.

b) Con alta frecuencia se alude a una estrategia psíquica que será llamada coraza resistente, referida a una envoltura psíquica conformada por fuertes mecanismos defensivos, construida en prisión, a fin de no exponer sentimientos ni emociones ante los verdugos. Coraza que se podrá expresar bajo la forma de anestesia afectiva. Se buscó controlar las emociones y no permitir que la angustia se apoderara de los estados de ánimo, se imponía la necesidad de mostrarse fuerte. Los represores constantemente hostigaban al prisionero, lo ponían a prueba, buscaban «quebrarlo». Resistir fue la forma de sostener la integridad y no doblegarse, así como buscar intersticios de autonomía dentro del escenario de dominación, que los proveyera de apoyos para no claudicar. Según relatan, esta resistencia también fue alimentada por el mandato colectivo. En tanto quien no resistía podía recibir una mirada «enjuiciadora» por parte de sus compañeros.

Ahora bien ¿qué ocurre en el presente? La coraza que fue útil para mantenerse a salvo, forjada durante un tiempo demasiado largo y bajo un «fuego» demasiado fuerte, podría ser conservada el resto de la vida. En tal caso interferiría en los vínculos afectivos más significativos. Así como cumplió la función de evitar el dolor, también podrá evitar la expresión de sentimientos tiernos y amorosos y conducir al efecto no deseado de alejar a los otros.

c) Aunque racionalmente las personas se saben víctimas de un poder aplastante, es posible que mantengan sentimientos de autoinculpación que se expresan de diversas formas. La tortura toma la culpa como herramienta de destrucción de los sujetos. La gran trampa es que establece un dilema de doble vínculo: «Si hablo caen presos otros, mueren o los torturan y yo soy responsable, sobrevivo al costo de perder mi alma. Si no hablo, arrojo mi cuerpo a la muerte, pero mantengo mi integridad y mi dignidad». La alternativa es falsa porque si no habla puede morir, pero si habla también puede morir. La diferencia es que si habla carga con el desplome de sus propios valores.

Algún profesional establece una vinculación entre la autoinculpación que se observa en los pacientes y lo que pudo acontecer en el vínculo con los torturadores, o la relacionan con el hecho de haber experimentado sentimientos que se consideran miserables o inaceptables. Los prisioneros fueron culpabilizados por sus verdugos, quienes los responsabilizaron por lo que les sucedía: «Si no te hubieras metido en nada no estarías aquí». A través de la humillación fueron ubicados en el lugar de objetos despreciables y no-humanos. Quizá en algunas ocasiones se vislumbren aspectos internalizados que habrían sido depositados por el agresor, en los que aquella voz macabra aparezca como propia, pasando entonces el sujeto a torturarse a sí mismo. Françoise Sironi (2011), desarrolla lo que ha llamado «la influencia del torturador sobre el torturado». Observa que a los clínicos que trabajan con víctimas de tortura, les llama la atención que éstas otorguen tanta importancia a las palabras pronunciadas por los torturadores. Sostiene que las palabras que fueron pronunciadas durante el tiempo de la tortura "permanecen grabadas para siempre», «literalmente penetran su ser», «esas palabras los roen por dentro». La influencia del torturador se puede expresar de muchas otras maneras, 
considera Sironi, por ejemplo en pesadillas, afectar procesos mnémicos, o dañar la autoestima.

Por otra parte, se señala que la situación de tortura genera estados confusionales, que la sola duda acerca de qué se dijo o no se dijo puede mortificar al prisionero durante años. Otra fuente de autoinculpación es haber creído en la palabra de sus perpetradores. Entre sesión y sesión de tortura, era frecuente que un represor le hiciera creer al prisionero que quería ayudarlo, mostrándose gentil y engañando a la víctima, haberle creído puede ser motivo de autoflagelación.

d) Los principales efectos que dejó el tiempo de encierro y que se pueden apreciar en el presente son pasividad y aislamiento. El sistema autoritario de la prisión no le permitía al sujeto tomar decisión alguna. Se tornaba enloquecedor porque al tiempo que lo sometía a la obediencia y la rutina, lo conducía a la arbitrariedad y la incertidumbre constantes. Algunos entrevistados han observado aspectos de pasividad en los pacientes, quienes se refugian en rutinas aseguradoras, o manifiestan excesiva dependencia hacia sus seres queridos. Otra característica que se observa es la tendencia al aislamiento. Los profesionales mencionan algunas formas en que se presenta: aislarse respecto a la familia, aislarse en la seguridad del grupo de pares (ex presas/os), tener dificultades para integrarse en diferentes ámbitos de la sociedad, aislarse en el alcohol, al extremo de quienes se han aislado en el delirio. Se podría ubicar en esta línea cierta tendencia al gueto observada por algunos, se agrupan con quienes compartieron la prisión, con quienes se producen fuertes identificaciones. El par le permite ahorrarse gran parte de las explicaciones, en comparación a quienes no pasaron por la prisión. La tendencia a vincularse sólo con los iguales podría relacionarse al hecho de haber permanecido por años dentro de un sistema maniqueísta, un mundo dicotómico de compañeros y enemigos. Lo que puede dar lugar a una subjetividad polarizada en la que se hace difícil encontrar matices, modelo de percepción de la realidad que dentro de la cárcel resultó funcional porque permitió protegerse, pero que posteriormente pudo ocasionar conflictos en los vínculos, en tanto las personas no son puramente buenas o puramente malas.

e) Existe amplia literatura que da cuenta de las huellas en el cuerpo que se pueden observar en quienes han sido torturados. Los entrevistados refieren a enfermedades físicas como ser: patologías osteoarticulares, osteomioartritis, dolores crónicos, afecciones neoplásicas, enfermedades auto-inmunes. En el cuerpo quedan huellas de la violencia, de la invasión del otro en los espacios más íntimos; del poder y el dominio del otro sobre sí mismo. Un profesional refiere el miedo al dolor físico, así como a aquellos procedimientos que implican manipulación del cuerpo por parte de terceros, en los que la persona se halla en una posición pasiva y a merced del otro (médicos, odontólogos, enfermeras), los que podrían ser vividos imaginariamente como amenaza a la integridad.

\section{Sobre las Políticas Públicas de Reparación}

Se abordarán los impactos, que a ojos de los profesionales, producen en los pacientes los procesos de Reparación. Se toma la noción Reparación en el sentido teórico que propone el derecho internacional, referida a las obligaciones que los Estados tienen para con las víctimas que fueron generadas por su accionar violatorio. El Estatuto de Roma, de la Corte Penal Internacional, en el artículo 75 desarrolla los alcances de la Reparación, fundada en tres principios: restitución, indemnización y rehabilitación. 
31 La mitad de los entrevistados observan que los hechos desarrollados en el plano macrosocial, vinculados al procesamiento socio-histórico de los sucesos provocados por el terrorismo de Estado, impactan e impulsan a la consulta.

[...] lo específico es la necesidad de analizar las incidencias del discurso social dominante sobre los afectados y sobre la propia práctica profesional. Entendemos por discurso social dominante al conjunto de ideas e interpretaciones sobre una situación dada elaboradas y difundidas por los sectores que detentan poder. Este discurso social interviene como un factor intrínseco en la elaboración de la situación traumática. (Kordon et al., 1995: 180, 181)

32 Mayoritariamente los entrevistados dan cuenta de la indiferencia de la sociedad y de la falta de voluntad política en materia reparatoria. En ocasiones los ex prisioneros pueden ser culpabilizados por miembros de sus familias o por diversos sectores de la sociedad. Hasta el día de hoy cargan con un manto de sospecha. Aún sobrevuela en el aire la llamada "teoría de los dos demonios» ${ }^{1}$ y no solo desde boca de los represores, también desde agentes de gobierno. Aunque no se niegan los avances que ha habido en el país en materia de reparación, los clínicos no observan suficiente voluntad política, ni que esta política pública sea jerarquizada o se den señales claras de repudio contra la violencia perpetrada por el Estado en el pasado reciente.

33 Se plantea el desafío de que la memoria no quede encerrada en el mundo de las víctimas, que circule por otros espacios sociales, que otros actores y otras generaciones la hagan propia. Serán necesarios procesos colectivos, tanto a instancias de quienes diseñan las políticas públicas o por iniciativas de actores y movimientos sociales. De lo que se trata es de integrar ese pasado al pasado de la nación, conjugar memoria colectiva con memoria histórica.

34 El advenimiento de los gobiernos progresistas facilitó la tarea de recordar y comenzar a sanear. Es de destacar que los entrevistados consideran saludable que los pacientes se agrupen con la intención de hacer conocer lo que vivieron: trabajando en pos de la memoria colectiva, en la creación de obras artísticas, presentando denuncias judiciales, siendo partícipes de los procesos de reparación, promoviendo intercambios intergeneracionales. Según expresan, esto significa no quedarse solo y sufriente, sino la posibilidad de transformar el dolor en apuestas más vitales. Se constata que estos movimientos son liberadores y permiten repartir algo de la «carga» que como resultante del silencio, el olvido y la impunidad, ha sido encapsulada en las víctimas directas y en sus familiares más cercanos. Un entrevistado expresa que no considera reparador lo que está inspirado en la venganza, lo que lleva a que la víctima se transforme en victimario. Tampoco produce empatía el relato descarnado o morboso, por el contrario, puede producir reacciones de bloqueo o de huida.

\section{Sobre la Pensión Especial Reparatoria}

Se consultó a los profesionales respecto a los impactos subjetivos de la llamada Pensión Especial Reparatoria (PER) percibida por los beneficiarios de la Ley n. ${ }^{\circ} 18.033^{2}$. Se señala que durante los primeros años en que se comenzó a otorgar esta pensión, era frecuente que los ex prisioneros se negaran a recibirla, arguyendo «que no habían militado para recibir dinero». Se hizo necesario que transcurriera un tiempo para que pudieran comprender que no se trataba de un "obsequio», sino de un derecho, establecido como un logro a través de los avances del derecho internacional. Sin embargo, los entrevistados 
continúan observando ciertos sentimientos de vergüenza o pudor por recibir este dinero, aunque actualmente en menor escala. En términos generales hay acuerdo al considerar que la PER ha significado un aliciente que ha permitido mejorar la calidad de vida de estas personas. Sin embargo, muchos se quejan porque en su aplicación se vislumbran situaciones de injusticia (no todos la cobran). Es importante aclarar que no se trata de una indemnización por haber sido víctimas de tortura o encarcelados por sus ideas políticas, sino que sólo tienen acceso a la misma quienes demuestren que además de su calidad de víctimas del terrorismo de Estado, sufrieron daño laboral. La ley establece un tope, quienes perciben sueldos mayores no tienen derecho a percibirla. Otro motivo de malestar se debe a que la ley no permite a los sujetos sumar la PER con la jubilación que han generado a través de los aportes laborales realizados a lo largo de su vida. A la hora de retirarse, tendrán que elegir entre percibir la jubilación o la PER.

En general se considera justo que el Estado brinde este tipo de medidas paliativas frente a los daños ocasionados a los sujetos. Sin embargo, algunos manifiestan sospechas o dudas sobre las intenciones de los gobiernos. Se preguntan si a través del dinero se estará intentando saldar la deuda moral y al mismo tiempo acallar a las víctimas. Se reclama que debería ofrecerse una indemnización a las víctimas de tortura y no una pensión limitada a quienes acrediten daño laboral. Se habla de la necesidad de procesos reparatorios en los que quienes han sido afectados tengan un rol protagónico, hagan valer sus derechos, así como, participen en la implementación y seguimiento de estas políticas ${ }^{3}$.

\section{¿Qué producen los Juicios?}

37 Los entrevistados refieren al valor simbólico que se desprende de la aplicación de la ley al interior de una sociedad, debido a que ordena, ubica en sus justos términos los hechos, así como por su valor ejemplarizante hacia los demás miembros de la comunidad. Al tratarse de crímenes de lesa humanidad no hay prescripción posible, siempre se está a tiempo de nominar a los sucesos por su nombre, de tomar aprendizajes, de que la barbarie sea repudiada, de sancionar el crimen y de que los responsables reciban condena.

Estos procesos judiciales activan diversos aconteceres: promueven el agrupamiento de quienes fueron victimizados, construyen memorias colectivas e históricas, modifican imaginarios sociales, proponen nuevos discursos sobre el pasado, combaten impunidades, promueven procesos de sanación social, generan alivio si se comprueba que la ley protege y sanciona a todos por igual.

39 Se resaltan ciertos efectos sanadores que surgen a partir de la denuncia judicial, debido a que la persona que en la tortura fue humillada y «cosificada», pasa a ubicarse en el lugar de ciudadana que ejerce sus derechos y exige el cumplimiento de la ley. Se producen efectos de dignificación cuando los denunciantes son escuchados por un Poder del Estado, cuando se cree en su palabra, se aplica Justicia y quienes quebraron la ley son responsabilizados por los actos de barbarie cometidos.

Sin embargo, también se resalta que el proceso de la denuncia puede resultar por demás removedor, se observan fuertes sentimientos de angustia, temores, momentos en que se revive lo traumático. Los entrevistados señalan que en ocasiones puede surgir descompensación física y/o psíquica, o aparecer importantes montos de ansiedad de tipo paranoide. Es posible que no todas las personas puedan embarcarse en el derrotero de la denuncia. Algunos tendrán que preguntarse si podrán o no emprender ese camino. Habrá 
quienes que, debido a causas de diversa índole, no podrán sostenerlo. Durante el proceso de decisión, así como el tiempo que lleve la denuncia y el posterior a la misma, será positivo contar con apoyos; no vivirlos en soledad. Aquí cumple una labor primordial el acompañamiento psicológico o psicosocial.

Se señala que el Juicio puede retrotraer a los sujetos a las experiencias padecidas en los interrogatorios de la tortura, así como también a aquellos momentos en que fueron juzgados bajo la Justicia Militar. El modelo de «Justicia» conocido fue el que los procesó como «subversivos». Por tanto, será necesario desmontar internamente aquel esquema a fin de salir del lugar de sospechoso para pasar al lugar de denunciante.

Se observan efectos sanadores al desprivatizar el dolor, mover el recuerdo del espacio de la intimidad hacia el espacio público, habilitar a que un tercero opere de árbitro. Se destaca la importancia de que en Uruguay las denuncias se hayan hecho en forma grupal. Quizá porque el grupo permitió tomar impulso, sentirse más fuertes, prepararse junto a otros, vencer los miedos.

La mayor dificultad observada en estos juicios es que la Justicia no aplica consideraciones especiales para este tipo de víctimas y este tipo de juicios. Homologa estos juicios a otros cualesquiera, lo que puede conducir a contaminar el escenario y provocar situaciones de re-victimización. La experiencia uruguaya de los juicios dista mucho de la argentina, la que ha sentado jurisprudencia en torno al tratamiento que debe darse a los crímenes de lesa humanidad. En Uruguay el accionar ha sido muy desparejo, ha dependido de quienes administraron justicia, así como de los momentos políticos circundantes en cada oportunidad. Como señalan los clínicos, lo sanador de la denuncia es que construya Justicia, si a lo costoso de hacer la denuncia, se le agregan las trabas a lo largo del proceso y el no concluir en el procesamiento de los responsables, entonces todo resultará una farsa, no sólo para los denunciantes, también para la sociedad, al no otorgarle a estos juicios la importancia ética e histórica que se merecen. La tortura como acto abominable para no reproducirse necesita de sanción jurídica, moral y social.

\section{Reparación en Salud Mental}

Desde el año 2009, un equipo de profesionales ${ }^{4}$ de la Cooperativa de Salud Mental y Derechos Humanos (COSAMEDDHH) fue contratado por el Ministerio de Salud Pública, para brindar reparación en salud mental a las víctimas del terrorismo de Estado. Lo que luego, fue complementado con la sanción de la Ley n. ${ }^{\circ} 18.596$ (de Reparación Integral). Los psicoterapeutas de COSAMEDDHH valoran el peso simbólico que otorga el hecho de que sea el Estado quien se haga cargo de aportar alivio a los padecimientos de los sujetos. Sin embargo, se puede observar un alto nivel de disconformidad respecto a la forma en que se ha llevado a cabo. Opinan que cuando desempeñaban su labor desde la ONG Sersoc, podían desarrollar una tarea más integral, que sin embargo hoy su trabajo se limita sólo a la dimensión asistencial. Plantean quejas al gobierno por no haber mostrado suficiente voluntad política a la hora de priorizar la Reparación Integral; señalan que se han invertido escasos recursos, y que no han contado con referentes del gobierno con quienes interactuar y evaluar el programa.

Los psicoterapeutas sostienen que es a partir del año 2005, por primera vez -a diferencia del anterior período- que los pacientes se acercan a la consulta psicológica impulsados por el deseo de procesar vivencias de la tortura y la prisión. Surge como novedad el hecho 
de que revelen necesitar un espacio para expresar estas vivencias, lo que comienza a ser enunciado en forma explícita desde el motivo de consulta manifiesto. Los profesionales constatan que el tratamiento político-social de los traumatismos habilita nuevos procesamientos en las víctimas, que el procesamiento macro social de los traumatismos agiliza los procesos personales.

La necesidad de estas psicoterapias demuestra que lo traumático no conoce de temporalidades, que la aplicación sistemática de torturas, pudo ocasionar daños que podrán producir efectos en diferentes momentos de la vida. A su vez, se plantea que hay daños o re-victimizaciones que se continúan a través de la impunidad, y la negación de la gravedad de estos atroces crímenes. La impunidad en Uruguay contó con el agravante de que fue sometida al voto popular en dos oportunidades 5 , en las que no se alcanzaron los votos necesarios para su derrocamiento.

El desvelamiento o la denuncia ante la opinión pública, expuso la crudeza de los crímenes (hallazgo de restos óseos de detenidos-desaparecidos, aparición de niños y bebes secuestrados y apropiados, denuncias judiciales, procesamiento de responsables), habilitó la circulación de palabras en otros ámbitos de la sociedad, como ser: de enseñanza, laborales, barriales, familiares. Las nuevas generaciones se animaron a preguntar y el pasado se transformó en tema de interés para los medios de comunicación. De ese modo es que se irán construyendo discursos performativos que aporten nuevas formas de mirar aquel periodo de la historia. Quienes fueron violentados necesitan del reconocimiento social de la barbarie, que se legitimen discursos que reconozcan la ignominia. Los movimientos externos posibilitarán movimientos internos, como la emergencia de recuerdos o sentimientos, el contacto con vivencias escindidas y la necesidad de encausarlas.

\section{BIBLIOGRAFÍA}

CELS, Equipo de Salud Mental (Argentina) (1989), «Algunas Reflexiones sobre la tortura» en Instituto Latinoamericano de Salud Mental y Derechos Humanos, Derechos humanos: todo es según el dolor con que se mira, Santiago de Chile: Ediciones ILAS.

GIL Daniel et al. (1990), El terror y la Tortura, Montevideo: EPPAL Ltda, Colección Biblioteca de Psicoanálisis, Serie Textos.

GIORGI Víctor (comp.) (1995), Represión y olvido: efectos psicológicos y sociales de la violencia politica dos décadasdespués, Montevideo: Roca Viva Editorial, SERSOC.

KORDON Diana et al. (1995), La Impunidad. Una perspectiva psicosocial y clínica, Buenos Aires: Editorial Sudamericana.

KoRdon Diana, Edelman Lucilia, Lagos Darío \& KerSner Daniel (2002), «Trauma social y psiquismo. Consecuencias clínicas de la violación de derechos humanos», EATIP (Argentina), GTNM/RJ (Brasil), Cintras (Chile) \& SERSOC (Uruguay), Paisajes del dolor, Senderos de Esperanza. Salud Mental y Derechos Humanos en el Cono Sur, Buenos Aires: Polemos. 
MANGADo Lala \& RoBAinA María Celia (2012), «La emergencia de un prolongado y silenciado dolor», Las Laurencias, Montevideo: Trilce.

MARTIN Aldo (2002), «El fracaso del leteo o la imposibilidad del olvido», EATIP (Argentina), GTNM/RJ (Brasil), Cintras (Chile) \& SERSOC (Uruguay), Paisajes del dolor, Senderos de Esperanza. Salud Mental y Derechos Humanos en el Cono Sur, Buenos Aires: Polemos.

ONU (1987), Convención contra la Tortura y otros Tratos o Penas Crueles, Inhumanos o Degradantes.

ONU (2002), Estatuto de Roma de la Corte Penal Internacional.

SERPAJ (1989), Uruguay. Nunca Más. Informe sobre la violación a los Derechos Humanos (1972-1985), Montevideo: Altamira, 3. ${ }^{\text {ed. }}$

SIRONI Françoise (2011), Carrascos e Vítimas. Psicología da tortura, Sao Paulo: Terceira Margen. Traduçao do origina Sergio Salvia Coelho.

ULRIKSEN Maren (2006), «Capítulo VI. La transmisión del horror», J. Puget \& R. Kaës (comps.), Violencia de estado y psicoanálisis, Buenos Aires, México: Grupo Editorial Lumen.

VIÑAR Marcelo N. (2011), «El enigma del traumatismo extremo», Revista uruguaya de Psicoanálisis, $113,55-66$.

\section{NOTAS}

1. La Teoría de los dos demonios pretende explicar la violencia y el quiebre institucional de los años 70 a partir del enfrentamiento (o guerra) entre dos bandos o «demonios»: las organizaciones guerrilleras (o el comunismo internacional) y las Fuerzas Armadas. Esta teoría establece una secuencia causa-efecto - postula que los grupos guerrilleros «causaron» la reacción militarentre dos únicos actores ante una sociedad pasiva, inerme y en cierto modo sin responsabilidad política en la ruptura institucional.

2. Ley $n .^{\circ} 18.033$. Ciudadanos que no pudieron acceder al trabajo por razones políticas o sindicales entre el 9 de febrero de 1973 y el 28 de febrero de 1985. Recuperación de sus derechos jubilatorios y pensionarios.

3. Se hace necesario aclarar que este estudio no exploró con especificidad los impactos subjetivos de las indemnizaciones morales y económicas que concede la Ley de Reparación Integral n. ${ }^{\circ}$ 18.596, a determinados grupos de víctimas.

4. Ex-integrantes de la ONG Servicio de Rehabilitación Social (SERSOC), la que desde 1984 a 2009 tuvo a su cargo la labor de ofrecer atención en salud mental a las personas afectadas por el terrorismo de Estado.

5. La impunidad se establece a partir de la Ley n. ${ }^{\circ} 15.848$ ( «de Caducidad de la Pretensión Punitiva del Estado»), sancionada por el Parlamento en diciembre de 1986. Rápidamente una parte de la ciudadanía promueve un Referéndum a fin de eliminarla. Sin embargo, en abril de 1989 las urnas expresan el apoyo de la mayoría del electorado. Por otra parte, dos décadas más tarde en 2009, un Plebiscito intenta anular parte de esta ley, sin lograr que se alcancen los votos necesarios. 


\section{RESÚMENES}

Durante el tiempo del terrorismo de Estado, el método de disciplinamiento que utilizaron los represores para imponer sus ideas, fue el ejercicio sistemático del terror y sus principales instrumentos: la tortura y la prisión política prolongada. Las/os prisioneras/os sufrieron en las décadas de los 60, 70 y 80 la aplicación sistemática de tortura física y psicológica en interrogatorios, y tortura psicológica en forma permanente durante el tiempo de reclusión. Estas experiencias traumáticas, han dejado en los sujetos, en sus familias y en la sociedad, efectos que permanecen y que en ocasiones impulsan la demanda de consulta psicológica o psiquiátrica. Este texto recoge conocimientos que se desprenden de un estudio cualitativo en el que fueron entrevistados doce psicoterapeutas (psicólogos y psiquiatras), los que han acumulado la mayor experiencia en el país en lo que se refiere a la atención psicológica y psiquiátrica a ex presas/os políticas/os, experiencia que han desarrollada a lo largo de tres décadas. Se indagaron las características de las psicoterapias realizadas en el periodo que va del 2007 al 2012, así como también las problemáticas planteadas por quienes consultan. Se desarrollan los efectos tardíos de la tortura y la prisión hallados por los psicoterapeutas en los ex prisioneros y se expone la mirada de estos profesionales sobre algunas políticas públicas de Reparación que se realizan en el Uruguay.

During the State terrorism, the method of discipline used by the repressors to impose their ideas was the systematic use of terror and its main instruments: torture and long-term political imprisonment. In the 60's, 70's and 80's, the prisoners suffered from systematic use of physical and psychological torture during interrogations, and constant psychological torture during imprisonment. These traumatic experiences have affected them, their families and society, in lasting ways and that, sometimes, need to be treated with psychological or psychiatric consultations. This paper includes knowledge that emerge from a qualitative study conducted with twelve psychotherapists (psychologists and psychiatrists), who have the most experience in the country in psychological and psychiatric care for former prisoners and politicians, an experience they have developed over three decades. The characteristics of psychotherapies carried out in the period from 2007 to 2012 were investigated, as well as the issues raised both by the consultants and the consulted. Late effects of torture and imprisonment found by psychotherapists in former prisoners are developed in this paper, and also the view of these professionals on some public policies regarding the reparations that are developed in Uruguay.

Pendant la période du terrorisme d'État, la méthode de contrainte utilisée par les acteurs de la répression afin d'imposer leurs idées tint en l'exercice systématique de la terreur, au moyen des instruments principaux que constituent la torture et la détention prolongée. Les prisonniers/ ières ont subi pendant les années 1960, 1970 et 1980 l'application systématique de tortures physiques et psychologiques pendant les interrogatoires et des tortures psychologiques permanentes pendant le temps de leur réclusion. Ces expériences traumatiques ont eu chez les sujets, leurs familles et la société toute entière des effets durables, persistants et conduisant à l'occasion à la demande de consultations psychologiques ou psychiatriques. Ce texte parcourt les résultats de l'étude qualitative menée auprès des douze psychothérapeutes (psychologues et psychiatres) ayant accumulé, sur trois décennies, une grande expérience au niveau national en 
terme d'attention psychologique et psychiatrique portée aux ex détenus/es politiques. L'étude concernait les caractéristiques des psychothérapies réalisées entre 2007 et 2012 ainsi que les problématiques suggérées par les consultants et les consultés. Cet article explore les effets à long terme de la torture et de la détention prolongée sur les ex-prisonniers/ières du point de vue des psychothérapeutes et présente le regard de ces professionnels sur quelques-unes des politiques publiques de réparation menées en Uruguay.

ÍNDICE

Mots-clés: effets de la torture, réparations aux victimes, psychothérapie et réparation Palabras claves: efectos de tortura, reparación a víctimas, psicoterapia y reparación Keywords: effects of torture, reparations to victims, psychotherapy and reparation

\section{AUTOR}

\section{MARÍA CELIA ROBAINA}

Instituto de Psicología de la Salud, Facultad de Psicología, Universidad de la República 